\title{
"Core on deck!" The End of SODV and the Return of the JOIDES Resolution as the IODP Riserless Vessel
}

by Peggy Delaney and Sean Higgins

doi:10.2204/iodp.sd.8.06.2009

In February 2009, after a 3-year operational hiatus in order to undergo a major retrofit, the JOIDES Resolution (or simply the $J R$, as it has been called since 1985) reverberated with the trademark phrase, "Core on deck!". For the crew and technical staff aboard during the $J R$ 's sea trials cruise in January-February 2009, it brought shouts of joy and tears of relief from years of rebuilding the $J R$ in a Singapore shipyard, and a realization that we were "really" going back to carrying out international expeditions. But what does the phrase mean to marine geoscientists around the world? For most scientists, it means that one of the only tools to explore sediments and rocks in the deep sub-seafloor throughout the world's oceans is finally available again. This unique research facility is our community's equivalent to the Hubble telescope and provides the access we need to the deep ocean. Accumulating an impressive array of accomplishments, the $J R$ (Fig. 1) has served as the sole scientific drilling vessel for the Ocean Drilling Program (ODP, 1985-2003) and for the initial phase of riserless drilling for

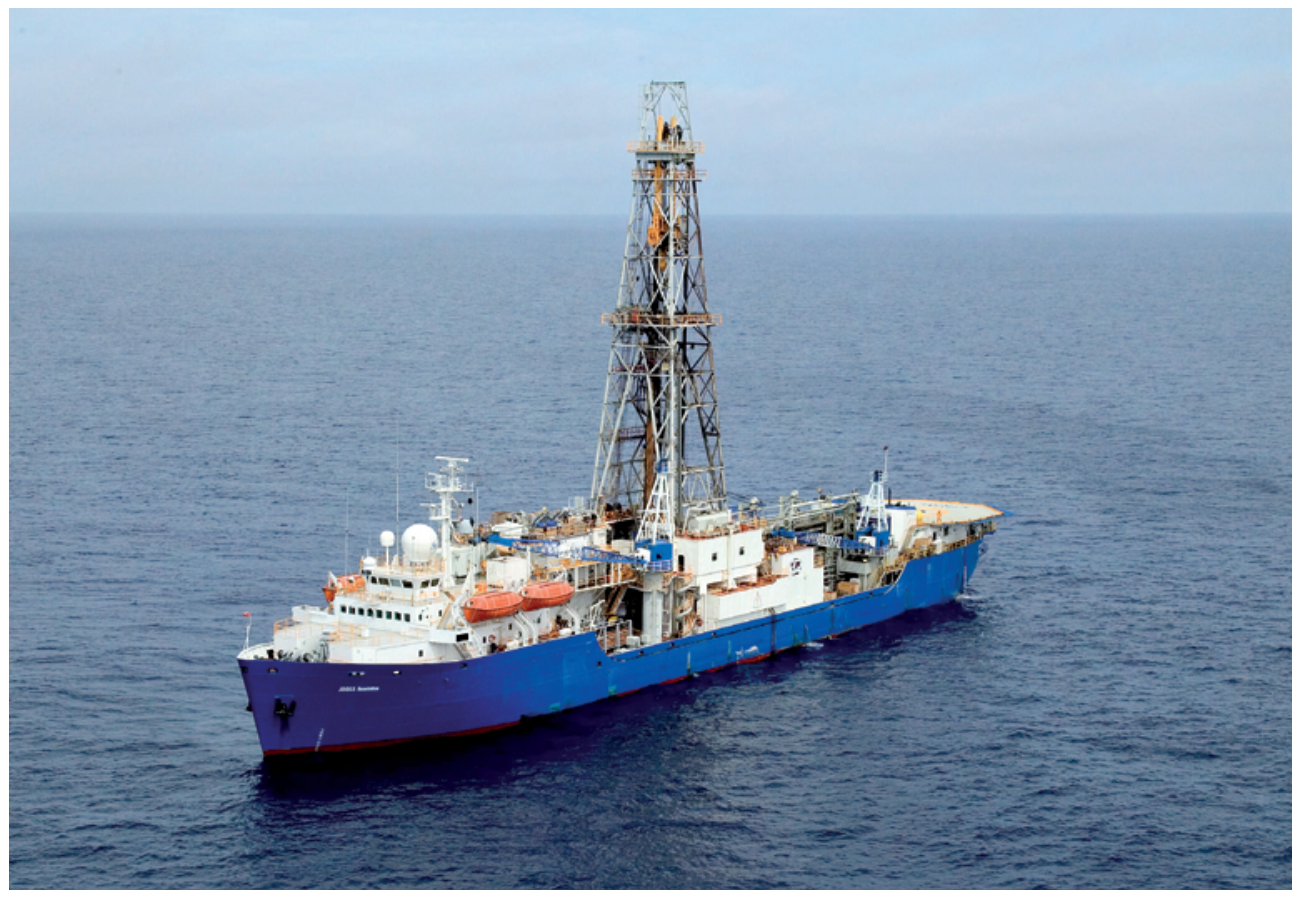

Figure 1. The pre-modernized JOIDES Resolution, an 143-m-long, dynamically positioned drill ship, with a derrick extending $>61 \mathrm{~m}$ above the water line, began operations in 1978 as the SEDCO/BP 471 and was converted in 1985 for use by the Ocean Drilling Program (ODP). The derrick height and overall size allow this vessel to be able to access a wide variety of ports, including passing under the Bridge of the Americas (Panama) and the Golden Gate Bridge (San Francisco, California). The name came from the JOIDES (Joint Oceanographic Institutions for Deep Earth Sampling) advisory structure and after the HMS Resolution, the vessel of exploration commanded by Captain James Cook. By the end of ODP and during initial IODP operations, the JOIDES Resolution $(J R)$ included a fully equipped lab stack, the scientific heart of expeditions, equivalent in its fitting and capabilities to shore-based research laboratories. the Integrated Ocean Drilling Program (IODP, 2003-2006). Over 120 expeditions since 1985 have retrieved samples encompassing a latitudinal range from $80.5^{\circ} \mathrm{N}$ to $70.8^{\circ} \mathrm{S}$, a water depth range from $85 \mathrm{~m}$ to nearly $6000 \mathrm{~m}$, sub-bottom ths as deep as $2.1 \mathrm{~km}$, and a total depth range (water depth plus penetration) over $6.9 \mathrm{~km}$.

As part of the United States' contribution to IODP, the National Science Foundation-through Geosciences Directorate and through its Major Research Equipment and Facilities Construction (MREFC) Account-provided more than $\$ 100$ million in funding for the conversion and upgrade of the $J R$ after it was selected in a public competition. This project, known by the acronym "SODV" (Scientific Ocean Drilling Vessel), has been an extended journey for those involved in bringing the $J R$ back to life, unlike any project any of us could have imagined when it started out in the spring of 2006 . Following on the heels of Hurricane Katrina and a worldwide boom in oil prices that led to the biggest shipbuilding boom in oil industry history, rebuilding the $J R$ could not have faced a more complex set of obstacles. Delivery of SODV came in January 2009, more than a year later than we had planned and only after near-heroic efforts from both the Transocean and Overseas Drilling Limited ship's crew and technical staff from the U.S. Implementing Organization (USIO) (Texas A \& M, Lamont Doherty Earth Observatory's Borehole Research Group and the Consortium for Ocean Leadership). The management of all these organizations also played a critical role in pushing for and accomplishing the SODV project.

The SODV project has its roots in a decade-long process of imagining the next many years of scientific ocean drilling 

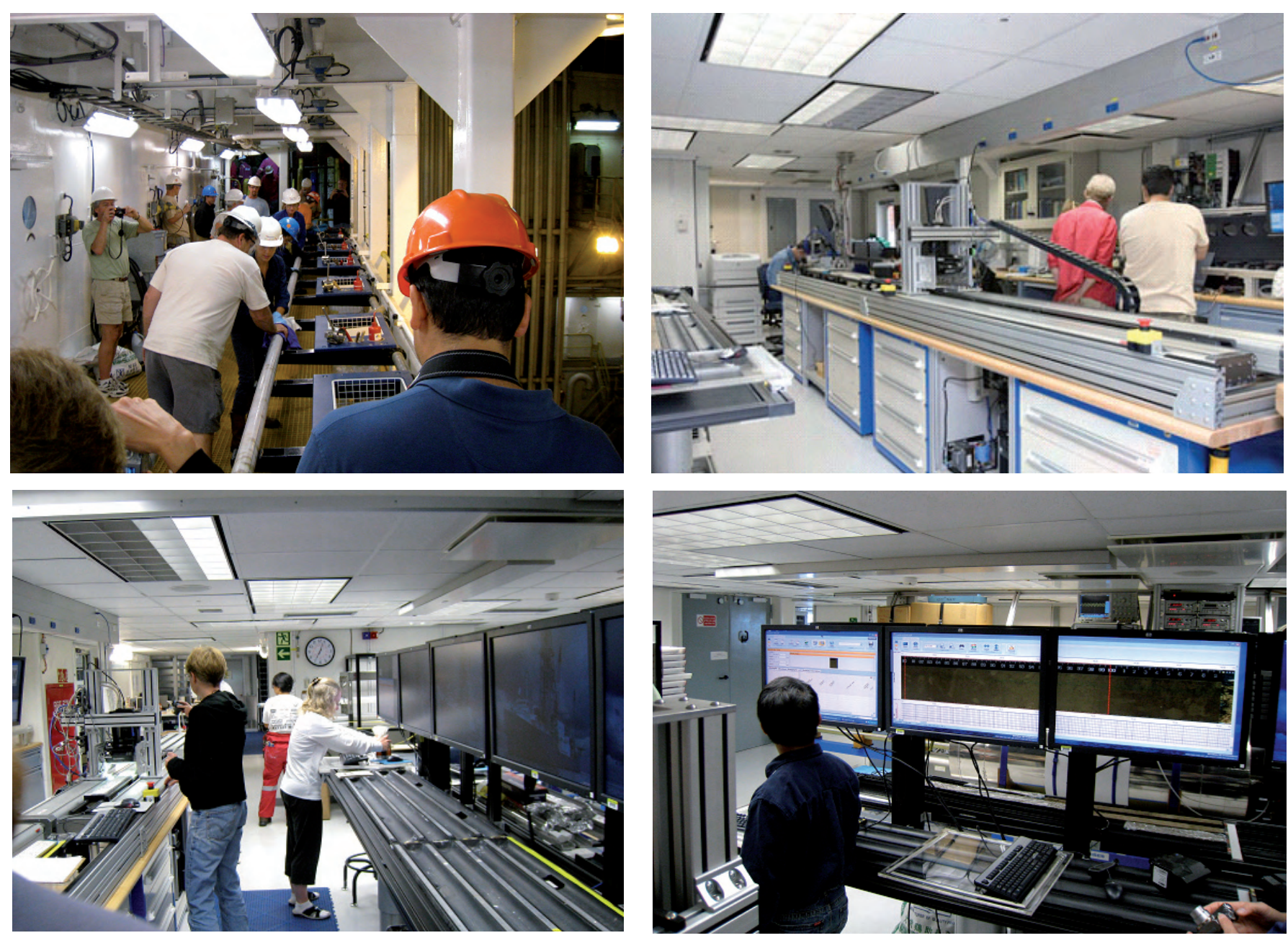

Figure 2. The Core Deck labs are but a portion of the all-new and larger lab facilities. The scientific equipment and systems in the labs were newly acquired, upgraded, or refurbished, based on experience gained in past expeditions and consultation with the international scientific advisory structure of IODP.

and translating this vision into a reality that guided the teams responsible for the conversion of a riserless drilling vessel for use by IODP. Recollecting the events, this all started in the Conceptual Design Committee (CDC) Report (2000) or the international Conference on Multi-Platform Exploration of the Ocean (COMPLEX) report in 1999 and, finally, the summarized requirements for a new riserless vessel in the USIO's Briefing Book (2005). This conversion project was guided by several overarching priorities (e.g. to provide more reliable riserless drilling vessel; to meet or exceed modern health and safety requirements; and science, sampling, and logging capabilities along with operational efficiency) and by a structure built to ensure science community input at multiple levels. One of the areas of greatest importance is preserving and enhancing the drilling, coring, sampling, and logging capabilities within the financial and physical limitations of the program. The project was focused on reliable, cost- and time-efficient drilling rig operations. Central goals were core quality and core recovery, including the ability to make holes with good progress in difficult lithologies where great depths must be achieved, and the ability to deploy the widest variety of downhole logging instruments and sampling tools.
In March 2009, the refurbished $J R$ arrived in Honolulu harbor on an unusually crisp morning after six weeks of sea trials that took the ship on a $>6000$-mile odyssey from an emotional departure in Singapore to Guam to the Ontong Java Plateau and finally to Hawaii. After the $J R$ just gained access to the science laboratory spaces in late November 2008 , installation of over sixty instruments, an entire IT infrastructure, and more than 100 new software applications was completed, thus readying the $J R$ (or nearly so) for its first science party since the end of 2005 (Fig. 2). This expedition (320T) was an intense testing period by both USIO staff and community participants, the Readiness Assessment Team (RAT) who produced an important baseline readiness report that documented current lab status and priority items that still needed attention. But, perhaps more importantly, the ship itself, the life supporting vessel systems, its critical drilling systems, newly refurbished derrick and passive heave systems, and new downhole logging system were also tested. After the ship had been guttee from the derrick forward, the $J R$ was indeed alive and kicking. All conversion and capabilities of the $J R$ are listed at http://www.oceanleadership.org/programs-and-partnerships/ship-conversion/ and some examples are given below: 


\section{Examples of ship conversion:}

- $34 \%$ increase in laboratory spaces (includes offices and conference space)

- Redesigned laboratory layout for better core handling and workflow

- Streamlined accessibility between laboratories and accommodations areas

- Enclosed, sound controlled core splitting and sampling room

- Improved core flow and integration of science activities on the Core Deck

- Refrigerated core storage for $>8000 \mathrm{~m}$ of core

- New ergonomic core description stations and software

- New and enhanced laboratories

- Refurbished sub-sea camera system

- Improved core handling capability

- New and expanded data servers and storage systems

- Refined and expanded berthing

- Updated safety and environmental systems

As of the start of Expedition 320 in March 2009 (the first of two expeditions focused on studying Cenozoic climate history of the equatorial Pacific), we no longer have to imagine what it might be like on the riserless scientific ocean drilling ship for the IODP in 2009 and beyond. Based on the many tours given in the first two port calls, scientists wondering if the $J R$ would really be different have seen the remarkable transformation of the ship, from the ship's new core (Fig.2), chemistry/biology, and downhole labs, to the light-filled galley on the main dec, to the all new integrated living quarters and the impressive new bridge (http://iodp. tamu.edu/labs/ship.html).

Ultimately, the true test of the $J R$ is its ability to obtain quality cores and geophysical logs in a variety of environments. Expeditions 320 and 321 immediately put the drilling systems, pipe handling, and coring systems to work in over $5 \mathrm{~km}$ of water in the central Pacific Ocean. The refurbished passive heave system, new wireline heave compensator, and a new rig instrumentation system to capture details of ship's drilling performance will all be put to the test in our upcoming expeditions (see back cover). The $J R$ has been retrofitted with modern technology and laboratories. In the coming years as it sails the world's oceans, it will again try to live up to its heritage (named after Captain Cook's HMS Resolution). The scientific progress that IODP is able to achieve with the $J R$ is now up to a new generation of marine scientists.

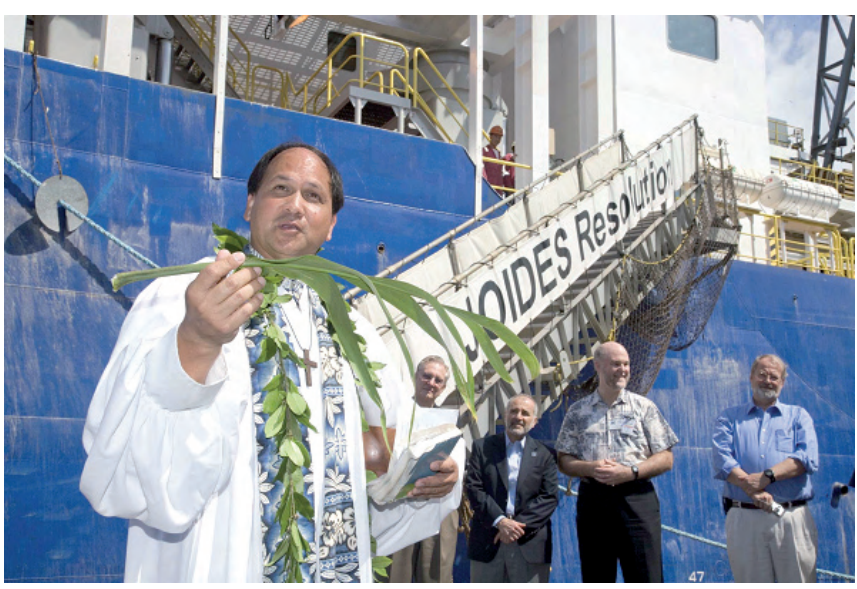

Hawaiian blessing of ship in May 2009 port call in Honolulu. From left to right: Kahu Kordel Kekoa (Chaplain for Kamehameha Schools Kapâlama), Arden Bement (Director of NSF), Bob Gagosian (President, Consortium for Ocean Leadership), Brian Taylor (Dean of SOEST, University of Hawaii), Bjorn Kjerfve (Dean of Geosciences, Texas A\&M Unviersity.

\section{Authors}

Peggy Delaney, Professor of Ocean Sciences, Ocean Sciences Department/Institute of Marine Sciences, 1156 High Street, University of California, Santa Cruz, Calif., U.S.A., e-mail: Delaney@ucsc.edu.

Sean Higgins, Associate Director, Ocean Drilling Programs, Consortium for Ocean Leadership, U.S. Implementing Organization, Washington, DC, U.S.A., e-mail: shiggins@ oceanleadership.org

\section{Related Web Links}

http://www.iodp-usio.org/About/default.html http://iodp.tamu.edu/labs/ship.html

Ship Conversion and Capabilities: http://www.oceanleadership.org/programs-and-partnerships/ship-conversion/ ship-conversion-and-capabilities/ 